DOI: $10.15593 / 2224-9354 / 2019.1 .15$

УДК 658.818

\author{
С.В. Комаров, А.В. Молодчик
}

ТРАНСФОРМАЦИЯ МАРКЕТИНГА

В ПЛАТФОРМЕННЫХ ОРГАНИЗАЦИЯХ: УПРАВЛЕНИЕ ПОВЕДЕНИЕМ ПОТРЕБИТЕЛЕЙ

\begin{abstract}
Появление платформенной экономики меняет отношения между производителем и потребителем. Это приводит к принципиальному отличию цифрового маркетинга от классического. В статье трансформация маркетинга в цифровой экономике рассматривается в зависимости от типа бизнес-модели организации, которая определяет способ взаимодействия с клиентами. На основе анализа российских и зарубежных компаний дана классификация типов бизнес-моделей платформенных организаций. Бизнес-модель информационной платформенной организации строится на взаимообратной связи между клиентом и организацией на основе запросов клиента. Бизнес-модель торговой платформенной организации строится на основе удобства товарного предложения и логистики. Коммуникационная платформенная организация выполняет роль посредника между потребителями и производителями услуги. В бизнес-модели сервисной платформенной организации клиент сам формирует набор необходимых ему сервисов из предлагаемых компанией. В соответствии с этой классификацией было проведено исследование изменений в маркетинге данных организаций. Эти изменения при переходе на платформу связаны, соответственно, с микромаркетингом потребителей, персонализацией предложения, максимальной связью маркетинга с продажами и «вовлечением» клиентов в создание новой сервисной платформы. Выводом является положение о том, что платформа является особым механизмом управления поведением потребителей, а ее гибридная модель - инструментом развития бизнеса клиентов компании. С точки зрения управления платформа является технологически, с одной стороны, инструментом управления самоорганизацией пользователей, с другой стороны, инструментом развития бизнеса клиентов компании. Именно это определяет сетевой эффект платформенного бизнеса. Результаты исследования получены на основе эмпирического анализа Пермского филиала 2ГИС.

Ключевые слова: платформенная организация, цифровой маркетинг, таргетирование, персонализация предложения, вовлечение потребителя, гибридные платформы, самоорганизация потребителей.
\end{abstract}

Становление цифровой экономики связано с новой концептуальной основой технологии ведения бизнеса - цифровой платформой. Это порождает кардинальные изменения финансовых инструментов и рынков. Динамика роста компаний, работающих в сфере цифровой экономики, отчетливо это доказывает: капитализация топ-10 компаний возросла с 1995 по 2015 год в 138 раз с 16,2 до 2242,8 млрд долл. [1]. Изменения в цифровой экономике связаны, прежде

(C) Комаров С.В., Молодчик А.В., 2019

Комаров Сергей Владимирович - д-р филос. наук, профессор кафедры менеджмента и маркетинга ФГБОУ ВО «Пермский национальный исследовательский политехнический университет», e-mail: philos.perm@gmail.com.

Молодчик Анатолий Викторович - д-р экон. наук, профессор, завкафедрой менеджмента и маркетинга ФГБОУ ВО «Пермский национальный исследовательский политехнический университет», e-mail: mavperm@gmail.com. 
всего, с изменением отношений между производителем и потребителями, что влечет за собой трансформацию привычных задач маркетинга в организации в отличие от классического маркетинга. По мере роста пользователей цифровой платформы возрастает эффективность целевого продвижения, увеличивается количество разрабатываемых на платформе предложений и сервисов, что, в свою очередь, привлекает еще большее количество клиентов. Иначе говоря, срабатывает сетевой эффект домино (рис. 1) [2].

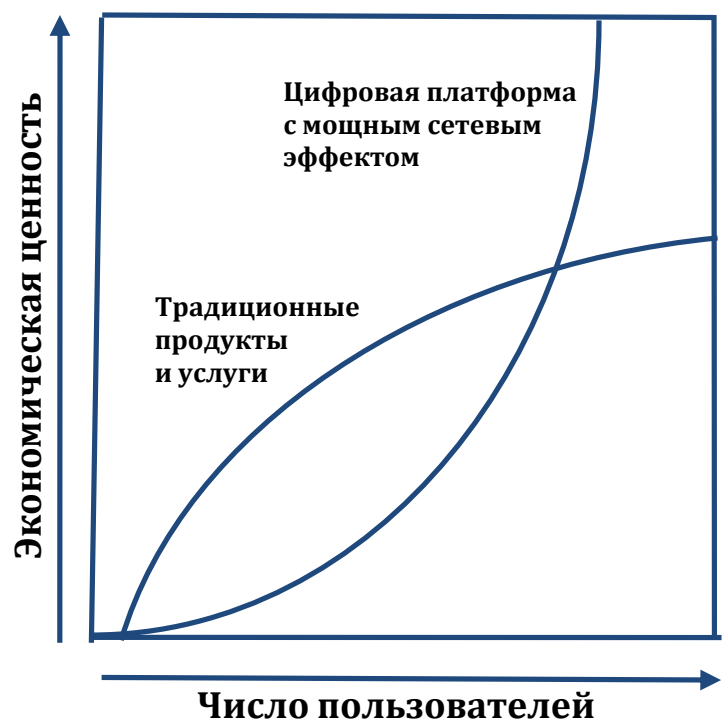

Рис. 1. Выгода от роста клиентской базы

Целью данной статьи является исследование трансформации маркетинга в современной цифровой экономике. Рассматриваются виды платформенных компаний и их особенности, которые обусловливают изменение функции, методов и инструментов маркетинга.

Модели платформенных компаний. Можно выделить несколько моделей платформенных организаций.

1. Информационная платформа. Компания обеспечивает поиск нужной информации по запросу пользователя платформы. Примерами таких наиболее известных компаний являются Google, Yandex. Бизнес-модель информационной платформы представлена на рис. 2.

Как правило, такими информационными платформами пользуются сотни миллионов пользователей. Специальные программы, анализируя запросы потребителей, формируют профиль предпочтений клиента и предлагают ему индивидуально сформированный пакет рекламных предложений. Реклама оплачивается рекламодателями, размещающими на платформе свои предло- 
жения. Кроме того, на платформе накапливается и обрабатывается огромный банк данных, содержащий аналитическую информацию о рынках, товарах, потребителях и т.д. Такая аналитика предоставляется и оплачивается по запросу компаний для их маркетинговых нужд.

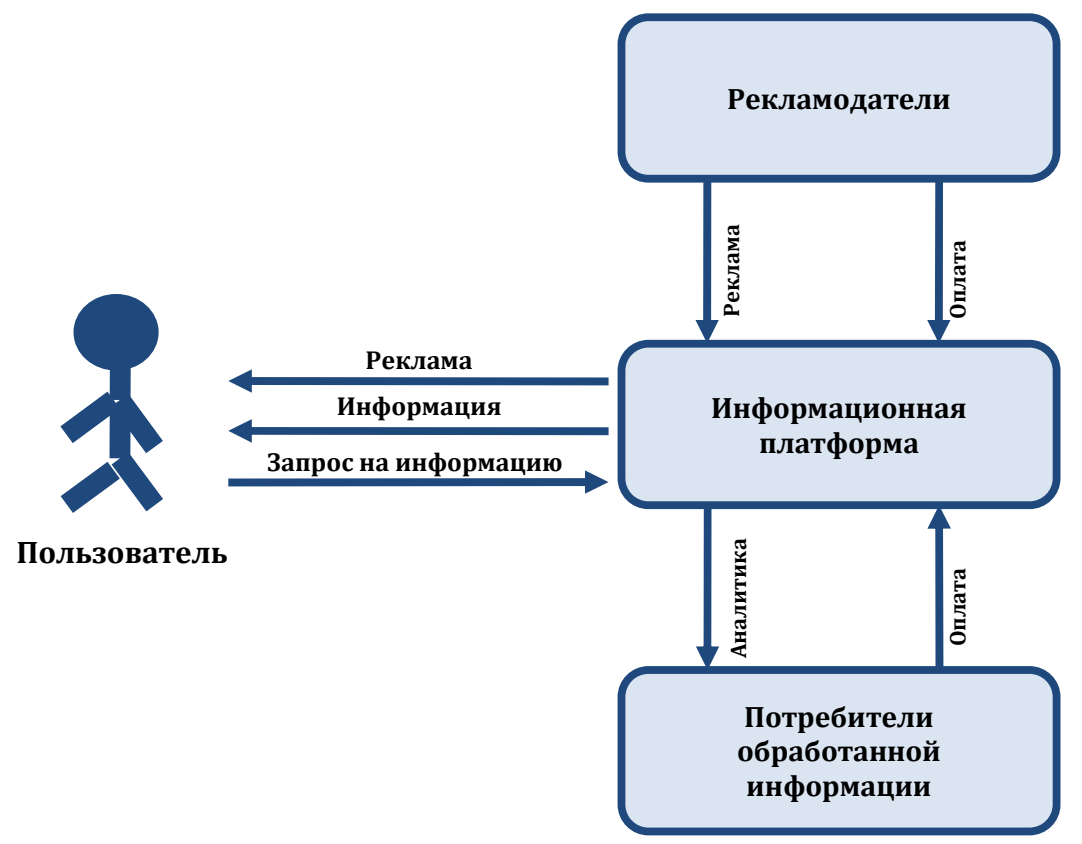

Рис. 2. Бизнес-модель информационной платформенной компании

Особенность данной бизнес-модели в том, что основная информационная услуга, производимая компанией, пользователям оказывается бесплатно, но благодаря генерированию платформой огромной аналитики и индивидуального формирования пакета рекламы, платформенная компания получает сотни миллионов долларов от рекламодателей и потребителей аналитики. Кроме того, данный тип платформенных компаний представляет пользователям целый ряд бесплатных и платных сервисных услуг.

2. Торговая платформа. Интернет-торговля сегодня одна из самых динамично развивающихся отраслей экономики. Лидерство здесь захватили платформенные глобальные супергиганты Amazon, Alibaba и другие аналогичные компании. Бизнес-модель здесь практически не отличается от бизнесмодели традиционной торговой компании (рис. 3).

Отличие заключается в качестве всех процессов и удобстве для потребителя. Во-первых, это огромный ассортимент товаров, которые можно приобрести, не выходя из дома, практически от любого производителя разных стран мира. Во-вторых, удобная форма оплаты, низкая цена и доставка товаpa. В-третьих, гарантия качества и возможность возврата товара. Данная мо- 
дель не требует огромной сети магазинов, имеющих свои площади и персонал, что значительно снижает затраты, а значит, и цену товара.

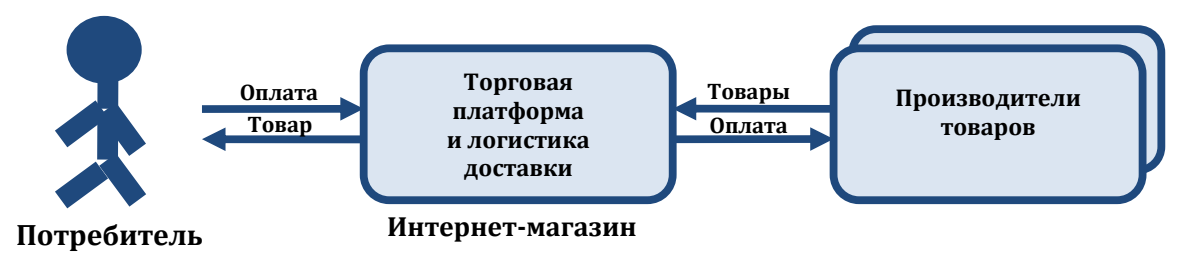

Рис. 3. Бизнес-модель торговой платформенной компании

3. Коммуникационная платформа. Согласно этой бизнес-модели платформенная компания выполняет роль посредника между потребителями и производителями услуги (рис. 4). Наиболее известны сегодня компании такого типа - Uber и Airbnb.

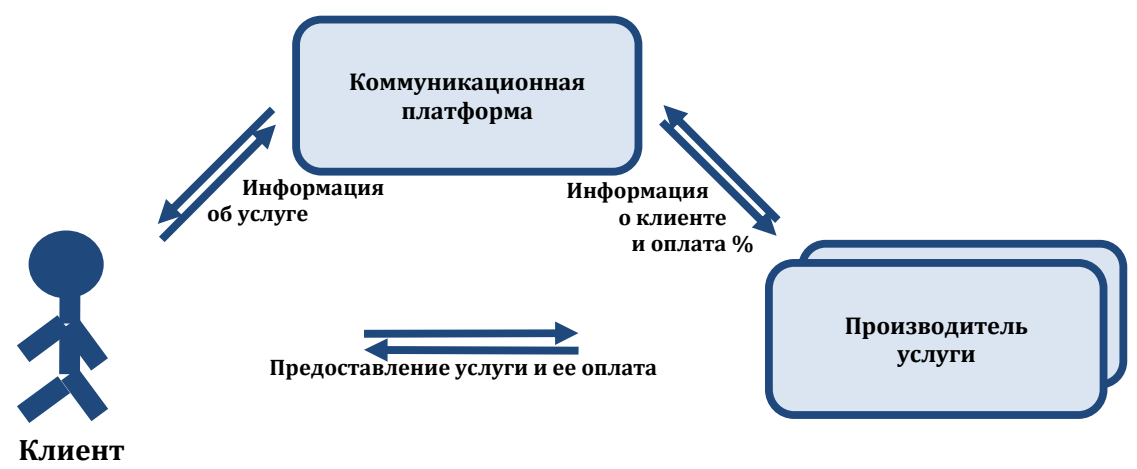

Рис. 4. Бизнес-модель коммуникационной платформенной компании

Сама платформенная компания практически исключена из производственного процесса оказания услуги (см. рис. 4). Она не имеет своих производственных мощностей - автомобилей или квартир, а следовательно, затрат на их приобретение, эксплуатацию, страхование. Она только осуществляет соединение потребителя с компанией или физическим лицом, предоставляющим эти услуги. Эта новая бизнес-модель не только кардинально меняет управление отраслью, но и в разы повышает эффективность самого бизнеса и, главное, удобство и доступность для покупателя.

4. Сервисная платформа. Перечень сервисных услуг, оказываемых на базе интернет-технологий огромен, начиная от социальных сетей типа Facebook до микроплатформы айфона Apple. Сервисы разрабатываются платформенной компанией (или покупаются ей у других производителей) и их количество может быть очень большим, и в ряде случаев формироваться 
самим потребителем (рис. 5). При этом пользователь сам выбирает вид сервиса, формирует удобные для себя его параметры, производит оплату на счет компании. И это воспринимается им как извлечение максимума удовольствия от потребления данной услуги при минимуме затрат и времени.

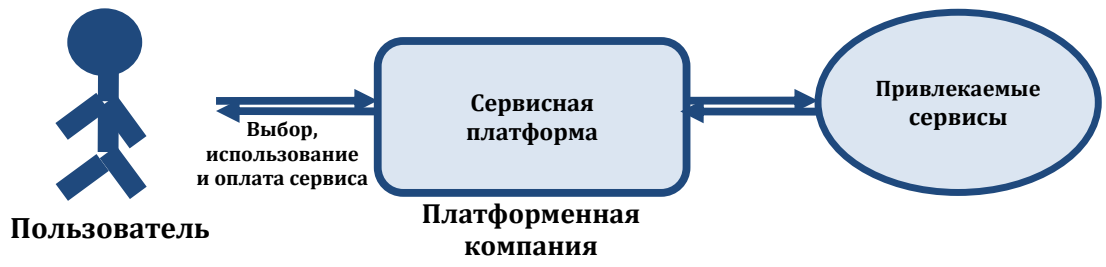

Рис. 5. Бизнес-модель сервисной платформенной компании

По сути дела при такой бизнес-модели пользователь вовлекается в сам процесс производства услуги, благодаря чему такая платформа становится самоуправляемой системой. Компания формирует платформу, поддерживает ее работоспособность и обновление, а клиент является ее важнейшим элементом.

\section{Трансформация маркетинга в платформенных организациях.}

1. Маркетинг в информачионной платформенной организации. Особенностью данной бизнес-модели является самостоятельный поиск потребителем нужной ему информации. С точки зрения маркетинга это означает следующее.

1. Благодаря накоплению огромных массивов данных (Big Data) о рынках, товарах и потребителях, платформы предполагают возможность осуществлять более точное маркетинговое таргетирование [3, с. 78]. Платформы допускают анализ поведения потребителя при посещении им соответствующих сайтов компании, что само по себе является автоматизированным маркетинговым исследованием [4]. При этом критерии сегментации потребителей могут быть «подсказаны» самой программой: все функции анализа, выявления профиля клиентов, определения особенностей их поведения и т.д. успешно могут быть переданы искусственному интеллекту. Такое максимальное таргетирование резко повышает эффективность маркетинга [5, с. 141-152].

2. Использование платформенных технологий в рамках такой бизнесмодели дает возможность максимальной персонализации предложения. Автоматизация маркетинга позволяет не только формировать группы клиентов, но делать для них индивидуальные предложения, кардинально увеличивая при этом конверсию [6, с. 72].

Анализ российской компании сотовой связи «Вымпелком» показывает, что в 2017 году она проводила одновременно около 6 тыс. маркетинговых компаний, т.е. делала конкретное предложение конкретной группе клиентов через 
определенный канал [3, с. 78]. Таргетирование и персонализация продаж в компании осуществляется путем обработки больших данных. Торговые предложения, сформулированные на основе обработки этих данных, дали следующие результаты: уровень удовлетворенности клиентов достиг 94 \%, а индекс NPS (Net Promoter Score, или индекс клиентской лояльности) продукта 65 \%. Руководитель соответствующего подразделения компании «Вымпелком» говорит: «Мы начали таргетирование продажи... когда научились работать с большими данными. Сейчас наши знания о клиенте позволяют сделать ему предложение, которое он с большой вероятностью примет» [7, с. 45-46].

2. Маркетинг в торговой платформенной организащии. Маркетинг платформенной торговой компании - это smarketing (sales + marketing). Автоматизация операций поиска и заказа товаров предполагает, что фактически это одна функция привлечения клиентов и реализации товаров посредством платформы. Расширенное предложение товаров, удобство заказа (дружественный сервис), экономия времени на оплате (возможность заказа из любой точки) обусловливает новые формы поведения потребителей, а именно:

- отказ от приобретения товаров традиционным путем и переход на покупки в интернет-магазинах,

- «совместные закупки»,

- уменьшение влияния традиционных средств продвижения за счет обмена контентом между потребителями.

Хороший пример перехода от традиционной к платформенной торговой организации демонстрирует компания «ВкусВилл» [8]. Теперь клиенты сами ищут необходимые им товары и услуги, сами организуют и осуществляют покупки и сами выбирают интересующую их торговую и рекламную информацию [9]. Стимулирование покупок осуществляется за счет лучшего технологического, более удобного и дружелюбного дизайна интернет-сервисов. В частности, как отмечают специалисты, торговые компании все больше используют при этом видеомаркетинг, поскольку видео - более комфортный способ потребления контента. Это связано именно с тем, что визуальный формат, являясь более ярким, может более убедительно рассказывать об особенностях товаров и услуг, предоставлять захватывающие истории про продукты и бренды. К тому же видео - основной язык молодежи [3, с. 80].

С точки зрения маркетинга это означает, что интернет-платформы торговых компаний ведут к полной автоматизации взаимоотношений продавца и клиента. Так, один из клиентов американской компании Adgorithms, владелец марки белья Casabella, был недоволен снижением продаж и обратился к искусственному интеллекту. Через месяц после начала работы роботаалгоритма «Альберта» рентабельность инвестиций в цифровую рекламу увеличилась на $50 \%$, а объем затрат уменьшился на $12 \%$. Если раньше соцсети генерировали 5-10\% дохода Casabella, то после сотрудничества с роботом 
цифра увеличилась в 3 раза, а прирост покупок через Facebook составил $2000 \%$ ! Кроме того, через полгода клиентская база компании увеличилась на $30 \%$ [3, с. 79].

Сбербанк РФ к 2020 году также планирует 95 \% своих предложений делать на основе достоверной информации о клиенте, извлеченной из электронных баз данных (электронной истории взаимоотношений). В частности, планируется здесь составлять электронные профили клиентов, которые будут управлять интерактивной и индивидуальной «торговой компанией» [3, с. 79].

Все это вместе взятое ведет к использованию иных метрик маркетинга, отличных от традиционных показателей.

3. Маркетинг в коммуникационной и сервисной платформенной организации. С точки зрения маркетинга особенности коммуникационной и сервисной бизнес-модели очень близки: в случае коммуникативной модели клиент формирует запрос на услугу по своим требованиям, а в случае сервисной модели он из имеющихся сервисов формирует саму услугу. Поэтому главной особенностью маркетинга этих бизнес-моделей является вовлечение потребителя в процесс оказания услуги.

В этой сфере все большую роль играют соцсети и мессенджеры $[10,11]$. Причем по числу активных пользователей аудитория четырех самых популярных из них (WhatsApp, Viber, Telegram, WeChat) превышает аудиторию четырех самых популярных социальных сетей. Как показывает статистика, молодежь - главный пользователь информации - плавно перетекает в мессенджеры, проводя здесь на $40 \%$ больше времени, чем в социальных сетях $[12$, c. 21$]$.

По сути дела сами по себе соцсети и мессенджеры являются цифровыми платформами, предоставляющими клиентам определенные сервисы. Любой современный мессенджер - это не только канал общения, но и мультимедийный проект, своеобразная медийная платформа, в которую встроены различные сервисы, организующие жизнь пользователей. Иначе говоря, с точки зрения маркетинга мессенджеры объединяют в себе все функции маркетинга: коммуникационную, функцию продвижения, функцию продаж, предоставления нужных сервисов и т.д. Мессенджеры и социальные сети усиливают еще больше сетевой эффект в рамках коммуникационных или сервисной платформы за счет крауд-брендинга [13, с. 39]. Пользователи вообще являются не только основными потребителями контента и его обмена, а повторные посещения во много раз усиливают сетевой эффект платформы [14, с. 36].

Таким образом, проведенный анализ показывает, что трансформация функций маркетинга в зависимости от различных видов моделей платформенных организаций характеризуется следующими чертами:

- возможностью максимального таргетирования,

- персонализацией предложения, 
- фактическим совпадением с продажами,

- вовлеченностью клиентов в процесс производства услуги.

Поэтому маркетинг цифровой платформы связан с самоорганизацией пользователей и клиентов [15]. Платформа технологически не только предоставляет услуги, но и за счет своих сервисов может определять потребительское поведение. За счет этого происходит мультипликация сетевого маркетингового эффекта [16]. Понимание этого заставляет сделать нетривиальный вывод с позиции маркетинга: платформа сама по себе является инструментом управления поведением потребителей.

Управление поведением потребителей. Кейс 2ГИС. В подтверждение этих выводов нами был проведен анализ маркетинга Пермского филиала компании 2ГИС. Исследование проводилось на основе анализа статистической и аналитической информации компании и фокусированных интервью с руководителями служб маркетинга Пермского филиала.

Компания 2ГИС известна в России и за рубежом как информационнорекламная мультиплатформа, предоставляющая разнообразные услуги своим клиентам. Начиналась история компании в 1994 году как проект обычного городского справочника. Очень быстро издание стало выходить на различных электронных носителях. Затем компания стала охватывать страны СНГ. Новый интерфейс в стиле Office 2007 и Ribbon-панель сделали программу проще и привлекательнее. В 2012 году создаются партнерские сервисы, 3D-модели и новый дизайн карт. В следующем году приложение для iPhone попало в топ-25 приложений в России, работающих по версии компании Apple. A c 2014 года, 2ГИС это крупнейшая интернет-компания в России. В настоящий момент компания присутствует на рынках Украины, Казахстана, Киргизии, Кипра, ОАЭ, Чехии, Италии, Чили. Полная история компании представлена в источнике [17]. В настоящий момент компания представляет 35,1 млн собственных продуктов, 7 млн - аудитория партнерской сети. По данным за декабрь 2017 года число уникальных пользователей (MAU - Monthly Active Users - это число устройств, с которых был произведен запуск/посещение продуктов компании хотя бы 1 раз в течение месяца) 2ГИС в России в 2017 году приложений для ПК было 2,4 млн, мобильных приложений - 15,3 млн, онлайн-версий - 17,6 млн. В октябре 2016 года аудитория мобильного приложения 2ГИС в возрасте от 12 до 64 лет среди жителей городов с населением свыше 700 тыс. чел. составила 5,4 млн чел. В настоящий момент в рейтинге Mediascope (TNS) 2ГИС занимает 8-е место среди крупнейших мобильных приложений (Топ-15), млн чел. ${ }^{*}$ :

ВКонтакте ................................................................................ 10,6

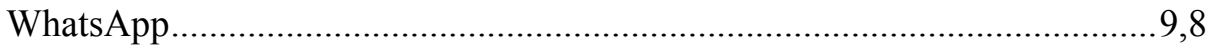

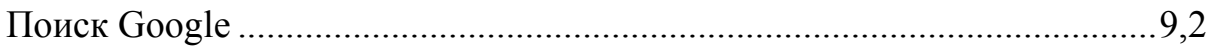

* Источник: по данным Mediascope (TNS) WEB-Index, Россия, 700к+, октябрь 2016 г., 12-64 лет, Monthly Reach, млн чел. 


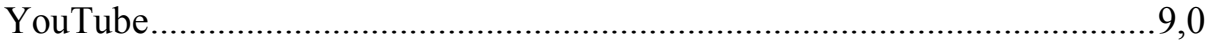

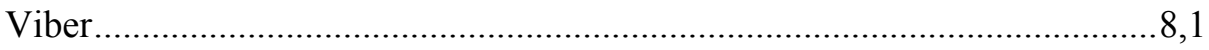

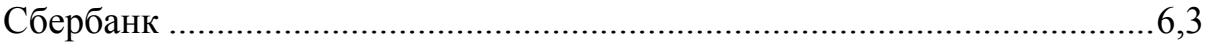

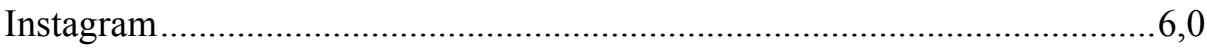

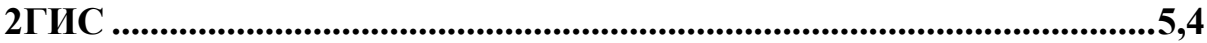

Google Maps .................................................................................

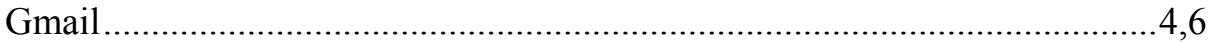

Mail.ru Почта ........................................................................... 4,4

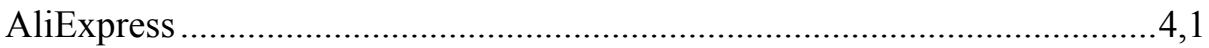

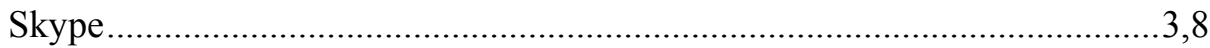

Clean Master ...................................................................................... 3,2

Google Диск ................................................................................. 3,2

В процессе развития компания в 2014 году перешла от информационной к сервисной мультиплатформе, которая объединяет в себе свойства информационной, коммуникационной и торговых платформ. Основная идея бизнеса заключается в предоставлении различных информационно-справочных сервисов и сервисов услуг для В2С клиентов и формирования спроса на услуги В2В клиентов, которые выступают рекламодателями. Прибыль компании образуется за счет рекламодателей В2В рынка, размещающих на платформе информацию о своих товарах и услугах, которой пользуются для удовлетворения своих потребностей клиенты В2С рынка. Примеры услуг, которыми пользуются клиенты В2С рынка от самой компании или ее партнеров, представлены в источнике [18-20].

Основная задача маркетинга компании привлечение рекламодателей В2В рынка и вовлечение в пользование сервисами платформы клиентов В2В рынка. Основная логика маркетинга компании строится по схеме, приведенной на рис. 6.

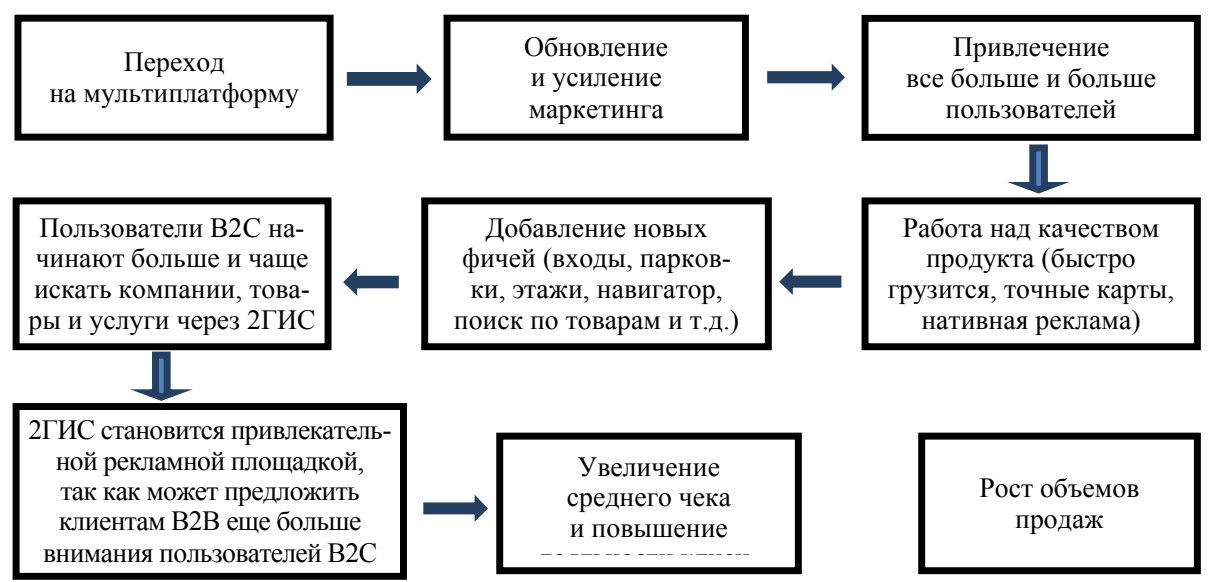

Рис. 6. Логика трансформации маркетинга компании 2ГИС 
Продвижение на рынке В2С теперь связано с «новым подходом» - это высокое медиадавление за счет охватных каналов: радио, транспорт, наружная реклама, ТВ. С 2018 года в этом ряду добавился новый канал - социальные сети. Ключевая цель в Перми на сегодня - увеличение количества скачиваний мобильных приложений. Для этого используются ресурсы блоггеров, популярных сообществ в социальных сетях, продвижение за счет медийных личностей. Продвижение на рынке В2В включает в себя регулярные бизнесзавтраки для текущих и потенциальных клиентов, интегрирование в сторонние бизнес-мероприятия (конференции, тренинги, мастер-классы), обновление формата рекламных, раздаточных материалов, а также приглашение на собственные мероприятия сторонних спикеров - профессионалов в своем деле, интересных клиентам В2В рынка. Все маркетинговые мероприятия обеспечиваются аналитической информацией за счет собственной информационной системы. Таким образом, маркетинг 2ГИС включает в себя: 1) персонализацию предложения для клиентов и пользователей; 2) таргетирование клиентов В2В рынка и сближение с продажами на этом рынке; 3) вовлечение клиентов В2С рынка за счет развития сервисов платформы.

Это развитие находит выражение в динамике маркетинговых и финансовых показателей компании. С переходом на мультиплатформу аудитория пользователей В2С рынка растет высокими темпами: общее количество пользователей в январе 2014 года в Перми было - 511 тыс., а в январе 2018 года - 890 тыс. чел. Из них доля MAU ПК - 28,8 \%, MAU Mobile - 34,2 \%, MAU on-line - 37,0 \%. Темп прироста MAU с января 2016 года по январь 2017 года составил 20,5 \%. Темп прироста показателя ВC (Business Connection), который характеризует активность пользователей и глубину использования продукта, за этот же период составляет 6,9 \%. Что касается рынка рекламодателей, то, хотя их число существенно не растет, составляя по рынку г. Перми около 1000 предприятий, в настоящий момент происходит увеличение как величины «среднего договора», так и стоимости самой рекламы. Общая динамика числа пользователей (количества обращений) компании представлена в табл. 1.

Таблица 1

Динамика числа количества обращений компании ПФ 2ГИС в г. Перми

\begin{tabular}{|l|c|c|c|c|}
\hline \multicolumn{1}{|c|}{ Показатель } & Dec-2014 & Dec-2015 & Dec-2016 & Dec-2017 \\
\hline Общая численность MAU & 606,086 & 760,235 & 742,837 & 859,661 \\
\hline Общее число ВС & $6,174,949$ & $5,578,666$ & $5,119,448$ & $5,461,826$ \\
\hline Общее число платных ВC & 302,698 & 218,786 & 226,287 & 254,241 \\
\hline $\begin{array}{l}\text { РД (рекламодатели / клиенты В2В } \\
\text { рынка) }\end{array}$ & 1,140 & 1,015 & 1,011 & 1,010 \\
\hline Платные ВС на РД & 266 & 216 & 224 & 252 \\
\hline
\end{tabular}

Источник: внутренние аналитические данные компании 2ГИС в Перми. 
Эти показатели коррелируют с показателями финансовых результатов Пермского филиала компании 2ГИС (табл. 2).

Таблица 2

Финансовые результаты ПФ компании 2ГИС

\begin{tabular}{|l|c|c|c|c|}
\hline \multicolumn{1}{|c|}{ Показатель } & 2014 & 2015 & 2016 & 2017 \\
\hline Годовой объем выручки, руб. & 147128904 & 128115029 & 126533649 & 149097562 \\
\hline $\begin{array}{l}\text { Годовой объем по новым клиен- } \\
\text { там, руб. }\end{array}$ & 8861806 & 6424802 & 5912988 & 7551017 \\
\hline
\end{tabular}

Проведенный анализ компании 2ГИС позволяет сделать следующие выводы:

1. Главным фактором является сам платформенный механизм, позволяющий совместить две главные функции маркетинга: аккумуляцию знаний о потребителях на основе их обращения к платформе, и использование технологической возможности самой платформы для формирования под выявленные запросы потребителей новых сервисов. В компании 2ГИС это выражается в постоянном интегрировании в мультиплатформу новых мобильных сервисов и интергации с сервисами компаний-партнеров. Это означает, что платформа технологически является своеобразным рефлексивно-креативным механизмом управления поведением потребителей.

2. Работа по гибридной бизнес-модели дает больший маркетинговый сетевой эффект: предоставление большего разнообразия и сервиса услуг потребителям рынка В2С привлекает клиентов В2В рынка, а размещение клиентами В2В рынка информации о себе на платформе делает ее еще более привлекательной для пользователей В2С рынка. Фактически это значит, что гибридная платформа сама по себе становится механизмом развития бизнеса клиентов компании.

\section{Список литературы}

1. Рожкова Д.Ю. Цифровая платформенная экономика: определение и принципы функционирования [Электронный ресурс] // Управление экономическими системами. - 2017. - № 10. - URL: http://uecs.ru/ teoriyasistem/item/4582-2017-10-1907-48-12 (дата обращения: 09.01.2018).

2. Янсити М., Лакхани К. Экономика платформ // Harvard Business Review. - 2017. - № 11. - C. 63-71.

3. Фуколова Ю. Новая эра маркетинга // Harvard Business Review. - 2018. Январь-февраль. - С. 77-81.

4. Эйден Э., Мишель Ж.-Б. Неизведанная территория: Как «большие данные» помогают раскрыть тайны прошлого и предсказывать будущее нашей культуры / пер. с англ. П.Миронова - М.: АСТ, 2016. - 351 с. 
5. Gupta Sunil, Donald R. Lehmann. Managing Customers as Investments. The Strategic Value of Customers in the Long Run. - N.Y., Pearson Education Inc., Wharton School Publishing, 2005. - 206 p.

6. Фуколова Ю. Деликатный таргетинг // Harvard Business Review. 2018. - Март. - С. 70-87.

7. Фуколова Ю. Стратегия точечных продаж // Harvard Business Review. 2017. - Март. - С. 40-47.

8. История компании «ВкусВилл» - URL: http://vkusvill.ru (дата обращения 09.01.2018).

9. Исследование целевой аудитории ТЦ «Семь пятниц» в рамках проекта исследования потребителей и разработки концепции маркетинга по Договору №147/2/МИ/01-15 от 22 марта 2016 г. / Ин-т повышения квалификации РМЦПК. - Пермь, 2016.

10. Социальные сети. В чем сила, лайк? / Л. Джон, Д. Мохон, О. Эмрих, Д. Шварц // Harvard Business Review. - 2017. - Август. - С. 64-72.

11. Вебер Л. Эффективный маркетинг в Интернете. Социальные сети, блоги, Twitter и другие инструменты продвижения в Сети / пер с англ. Е. Лалаян. - М.: Манн, Иванов и Фербер, 2010. - С. 256-287.

12. Шкаратан О.И. Ожидания и реальность. Социальная мобильность в контексте проблемы равенства шансов // Общественные науки и современность. - 2011. - № 1. - С. 5-24.

13. Холт Д. Брендинг в эпоху социальных сетей // Harvard Business Review. - 2016. - Май. - С. 31-41.

14. Альстайн М. ван, Паркер Дж., Чаудари С.П. Сетевой эффект как новый двигатель экономики // Harvard Business Review. - 2017. - Январьфевраль. - С. 28-36.

15. От самоорганизации к саморазвитию: смена парадигмы менеджмента / С.В. Комаров, А.В. Молодчик, Н.Ю. Бухвалов, К.С. Пустовойт [и др.]; Ин-т экон. УрО РАН. - Екатеринбург, 2013. - 257 с.

16. Одден Ли. Продающий контент. Как связать контент-маркетинг, SEO и социальные сети в единую систему / пер. с англ. В. Иващенко. - М.: Манн, Иванов и Фербер, 2014. - 384 с.

17. История компании 2GIS. - URL: http://info.2gis.ru/perm/company/ history (дата обращения: 09.01.2018).

18. 2ГИС запустил такси. - URL: http://info.2gis.ru/perm/company/news/ 2gis-zapustil-taksi (дата обращения: 09.01.2018).

19. «Аптеки 2ГИС» появились в Перми. - URL: http://info.2gis.ru/perm/ company/news/apteki-2gis-poyavilis-v-permi (дата обращения: 09.01.2018).

20. 2ГИС поможет сэкономить при покупке шин. - URL: http://info.2gis.ru/ kamchatka/company/news/2gis-pomozhet-sekonomit-pri-pokupke- shin (дата обращения: 09.01.2018). 


\section{References}

1. Rozhkova D.Iu. Tsifrovaia platformennaia ekonomika: opredelenie i printsipy funktsionirovaniia [Digital platform economy: Definition and principles of functioning]. Upravlenie ekonomicheskimi sistemami, 2017, no. 10, available at: http://uecs.ru/teoriyasistem/item/4582-2017-10-1907-48-12 (accessed 09 January 2018).

2. Iansiti M., Lakhani K. Economy platform. Harvard Business Review, 2017, no. 11, pp. $63-71$.

3. Fukolova Iu. Novaia era marketinga [New marketing era]. Harvard Business Review, 2018, January-February, pp. 77-81.

4. Aiden E., Michel J-B. Uncharted: Big data as a lens on human culture (Russ. ed.: Eiden E., Mishel' Zh.-B. Neizvedannaia territoriia: Kak "bol'shie dannye" pomogaiut raskryt' tainy proshlogo i predskazyvat' budushchee nashei kul'tury. Moscow, AST, 2016, 351 p.).

5. Gupta Sunil, Donald R. Lehmann. Managing customers as investments. The Strategic value of customers in the long run. N.Y., Pearson Education Inc., Wharton School Publishing, 2005, 206 p.

6. Fukolova Iu. Delikatnyi targeting [Delicate targeting]. Harvard Business Review, 2018, March, pp. 70-87.

7. Fukolova Iu. Strategiia tochechnykh prodazh [Point-of-sale strategy]. Harvard Business Review, 2017, March, pp. 40-47.

8. Istoriia kompanii "VkusVill" [History of the "VkusVill" company], available at: http://vkusvill.ru (accessed 09 January 2018).

9. Issledovanie tselevoi auditorii TTs "Sem' piatnits" v ramkakh proekta issledovaniia potrebitelei i razrabotki kontseptsii marketinga po Dogovoru №147/2/MI/01-15 ot 22 marta 2016 g. [The study of the target audience in the shopping centre "Sem' piatnits" within the project of consumer studies and development of marketing concepts under the contract no. 147/2/MI/01-15 of March 22, 2016]. Perm, Advanced training institute, 2016.

10. John L., Mokhon D., Emrich O., Schwartz D. Sotsial'nye seti. V chem sila, laik? [What is its power, like?]. Harvard Business Review, 2017, August, pp. 64-72.

11. Weber L. Marketing to the social web. How digital customer communities build your business. (Russ. ed.: Veber L. Effektivnyi marketing v Internete. Sotsial'nye seti, blogi, Twitter i drugie instrumenty prodvizheniia v Seti. Moscow, Mann, Ivanov i Ferber, 2010, pp. 256-287).

12. Shkaratan O.I. Ozhidaniia i real'nost'. Sotsial'naia mobil'nost' v kontekste problemy ravenstva shansov [Expectation and reality. Social mobility in the context of the problem of equal opportunities]. Obshchestvennye nauki $i$ sovremennost', 2011, no. 1, pp. 5-24.

13. Holt D. Branding in the age of social media. Harvard Business Review, 2016, May, pp. 31-41. 
14. Alstyne M. Van, Parker G., Chaudary S. Setevoi effekt kak novyi dvigatel' ekonomiki [Network effects as a new economic engine]. Harvard Business Review, 2017, January-February, pp. 28-36.

15. Komarov S.V., Molodchik A.V., Bukhvalov N.Iu., Pustovoit K.S. [et al.]. Ot samoorganizatsii k samorazvitiiu: smena paradigmy menedzhmenta [From self-organization to self-development: Management paradigm shift]. Ekaterinburg, Institute of economics UB RAS, 2013, $257 \mathrm{p}$.

16. Odden Lee. Optimize. How to attract and engage more customers by integrating SEO, social media, and content marketing (Russ. ed.: Odden Li. Prodaiushchii kontent. Kak sviazat' kontent-marketing, SEO i sotsial'nye seti v edinuiu sistemu. Moscow, Mann, Ivanov i Ferber Publ., 2014, 384 p.).

17. Istoriia kompanii 2GIS [History of the "2GIS" company], available at: http://info.2gis.ru/perm/company/history (accessed 09 January 2018).

18. 2GIS zapustil taksi [2GIS starts taxi service], available at: http://info.2gis.ru/perm/company/news/2gis-zapustil-taksi (accessed 09 January 2018).

19. “Apteki 2GIS" poiavilis' v Permi [2GIS drugstores have appeared in Perm], available at: http://info.2gis.ru/perm/company/news/apteki-2gis-poyavilisv-permi (accessed 09 January 2018).

20. 2GIS pomozhet sekonomit' pri pokupke shin [2GIS will help to save money when buying tires], available at: http://info.2gis.ru/kamchatka/company/ news/2gis-pomozhet-sekonomit-pri-pokupke-shin (accessed 09 January 2018).

Оригинальность $94 \%$

Получено 18.09.2018 Принято 12.10.2018 Опубликовано 03.04.2019

\author{
S.V. Komarov, A.V. Molodchik
}

\title{
MARKETING TRANSFORMATION IN PLATFORM ORGANIZATIONS: CONSUMER BEHAVIOR MANAGEMENT
}

The emergence of a platform economy is changing the relationship between producer and consumer. This leads to a fundamental difference between digital marketing and classical marketing. The article analyzes marketing transformation in the digital economy depending on the type of business model of the organization, which determines the way of interaction with clients. On the basis of the analysis of the Russian and foreign companies the types of business models of the platform organizations are classified. The business model of the information platform organization is based on mutual feedback between the client and the organization on the basis of client inquiries. The business model of the trading platform organization is based on the convenience of the product offer and logistics. Communication platform organization performs the role of an intermediary between consumers and service providers. In the business model of the service platform organization the client himself/herself forms a set of necessary services from the services offered by the company. In accordance with this classification a research of changes in marketing of these organizations was 
conducted. These changes in the transition to the platform are associated, respectively, with the micromarketing of consumers, personalization of the offer, the maximum connection of marketing with sales and "involvement" of clients in the creation of a new service platform. The conclusion is drawn that the platform is a special mechanism of consumer behavior management, and its hybrid model is a tool for business development of the company's clients. From the point of view of management, the platform is technologically, on the one hand, a tool for managing the self-organization of users, on the other hand, a tool for business development of the company's clients. This is what determines the network effect of the platform business. The results of the research were obtained on the basis of empirical analysis of the Perm branch of $2 \mathrm{GIS}$.

Keywords: platform organization, digital marketing, targeting, personalization of the offer, consumer involvement, hybrid platforms, self-organization of consumers.

Sergey V. Komarov - Doctor of Philosophy, Professor, Department of Management and Marketing, Perm National Research Polytechnic University, e-mail: philos.perm@gmail.com.

Anatoly V. Molodchik - Doctor of Economics, Professor, Head of the Department of Management and Marketing, Perm National Research Polytechnic University, e-mail: mavperm@gmail.com.

Received 18.09.2018 $\quad$ Accepted 12.10.2018 Published 03.04.2019 